\title{
PULMONARY VENOUS RETURN VIA THE SUPERIOR VENA CAVA
}

\author{
BY \\ J. E. O'N. GILLESPIE \\ From the City General Hospital, Leicester \\ Received September 16, 1941
}

The following case is reported as it shows an abnormality which, so far as I am aware, has not been recorded previously. In Abbott's Atlas of Congenital Cardiac Disease, 1936, no such case is described, the most closely related one showing pulmonary return into the right auricle via a dilated coronary sinus.

\section{History OF THE CASE}

The infant, a female, was born on March 21, 1941. During labour Dr. Hallum, who was in attendance, noted that there was some irregularity of the fœtal heart when bleeding occurred due to a lateral placenta prævia, the os being three quarters dilated. The weight at birth was $6 \mathrm{lb} .11 \mathrm{oz}$. and the condition was good, although the mother later recalled having been told by the nurse that the child's heart was not right. This observant nurse remains in obscurity. The feet were blue and remained so. When discharged nine days later it is recorded that no murmur was audible and there had been no attacks of cyanosis while in the nursing home.

At home breast feeding was stopped, due to the mother's having " insufficient milk," but bottle feeding was never satisfactory. She vomited practically every time after having taken half the feed, and would become white, with her lips slightly blue or even black. In her ninth week during bathing she appeared breathless and dead beat, but there was no colour change. One day she had a bluish patch on her left cheek. In two months she was only $20 \mathrm{oz}$. above her birth weight, and was losing. She was taken to a welfare centre, where she was used as a model for a gas-mask demonstration; immediately afte $r$ this she was very pale, and remained so until admitted to hospital two days later.

\section{Clinical Findings and Course in Hospital}

She entered hospital on May 27, 1941, as a case of inanition for investigation being then nine weeks old.

She was small and undernourished, with marked cyanosis of the extremities, 
slight cyanosis of the lips, and a high colour of the rest of the body. Her cry was feeble and almost aphonic. Respirations were 48 per minute, but were not laboured. There was reduplication of the first apical sound and some enlargement of the heart. The liver was palpable and enlarged. When crying, the right side of the mouth was drawn down more than the left. The pulse was regular; there were no thrills and no pulsation, except slightly at the apex ; there was no bulging of the chest, and the fingers were not clubbed, nor was there tortuosity of the vessels of the eye. The heart rate was regular and 150 per minute ; there was sinus rhythm with no sinus arrythmia. An electrocardiogram showed right axis deviation, large $P$ waves especially in lead II, and inversion of T in leads II and III : these findings suggested auricular and right ventricular preponderance.

The heart was enlarged, and the radiologist reported: "One cannot

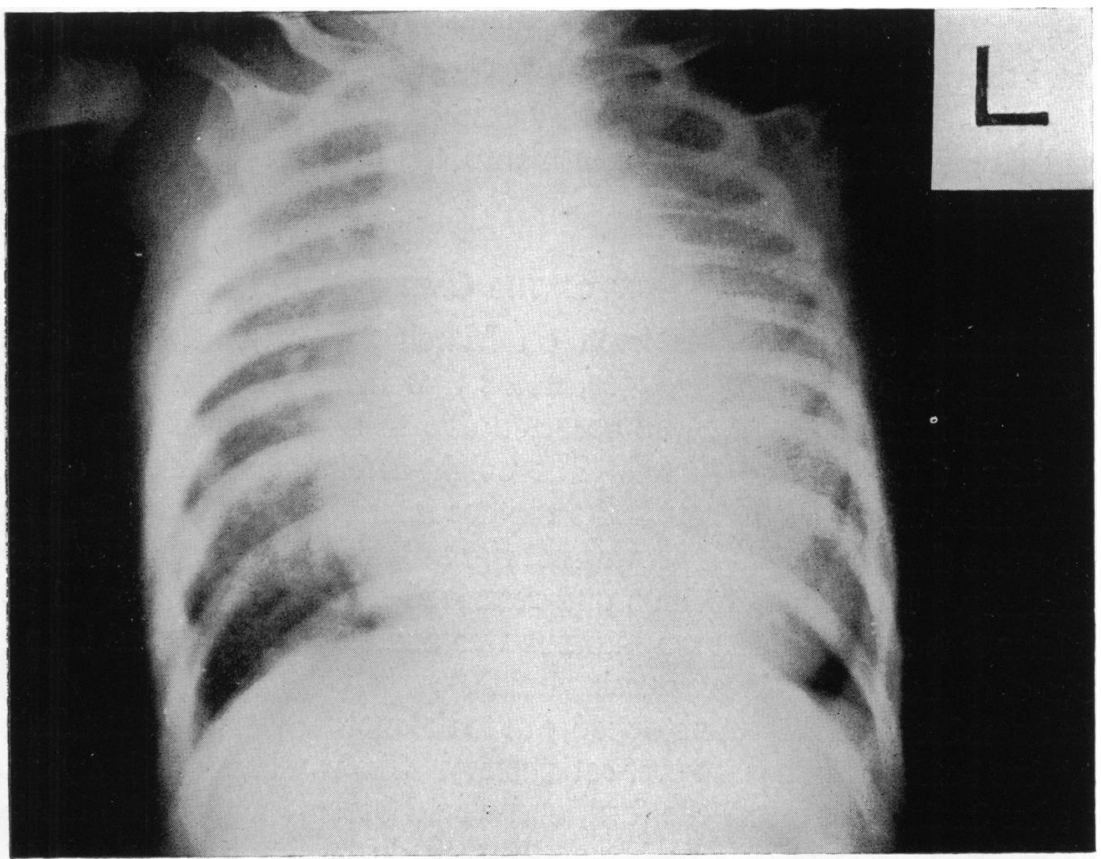

FIG. 1.-Radiogram of the heart taken at 6 feet.

exclude a congenital lesion, but there is no definite evidence of its existence." The hæmoglobin was 118 per cent., and the red blood cells 5,410,000 per c.mm. While blood was being taken for examination she became very cyanosed, almost black, and lay back exhausted ; her breathing was not more distressed than normal. After ten to fifteen minutes she gradually became better.

For the first six days feeding was difficult, as she became exhausted, and, on most occasions, would regurgitate half the feed. Cyanosis was not increased. Regurgitation did not occur after this date, although feeding remained difficult. On one occasion after a feed she became purple and distressed. The apex 
rate was rapid and regular. Oxygen through a nasal catheter appeared to cause some improvement.

By the ninth day the cyanosis had largely disappeared, although the respiratory rate remained about 60 per minute. The temperature rose to $99.5^{\circ} \mathrm{F}$., while the pulse fell to 130 per minute. There were numerous crepitations in both lungs, with diminution of breath sounds and dullness on percussion over the left lung. Sulphapyridine $0.5 \mathrm{~g}$. was given four-hourly. In place of the reduplicated apical first sound there was now a long, coarse, rumbling systolic murmur of fairly low pitch.

On the tenth day her colour was almost normal. The lungs remained very moist and the pyrexia slight. Immediately after the 6 p.m. feed her face became a greyish blue, her lips and ears were black, her face was twitching and her eyes squinting. For some hours she remained grey and exhausted ; her pulse was regular. On the eleventh day her breathing became very distressed, although there was no cyanosis. The appearances were suggestive of laryngeal or bronchial obstruction. She died at $5.30 \mathrm{a} . \mathrm{m}$.

The circulation is shown diagrammatically in Fig. 2.

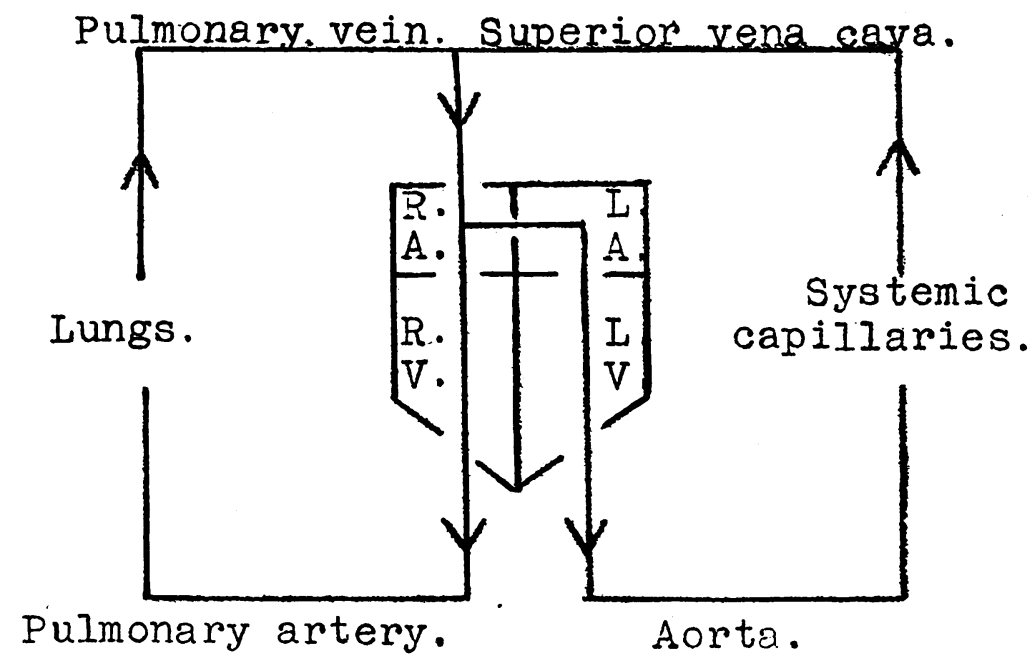

FIG. 2.-Diagram of the abnormal circulation.

\section{POST-MORTEM Findings}

There were several ounces of straw-coloured fluid in the pericardial and pleural sacs. The upper two to three feet of the jejunum contained about two ounces of blood mixed with partly digested food. The intestine was very congested. There was no blood in the stomach. The lungs showed mild bronchitis. Macroscopically there were no other abnormalities apart from the heart.

The heart was much enlarged, owing to hypertrophy of the right side, both auricle and ventricle... The heart weighed $52 \mathrm{~g}$. The lungs were joined together by a single pulmonary vein, and from the middle of this arose a thick trunk which united it to the lower and posterior part of the superior vena cava 
below the entry of the vena azygos. The pulmonary vein had no direct communication with the left auricle. The hypertrophied right auricle was thus receiving both arterial and venous blood. Many of these points can be well seen in Fig. 3. The sinus venarum was partly separated from the auricle proper by large valves of the superior and inferior vena cava. The pulmonary artery was of great size (about $32 \mathrm{~mm}$. in circumference). The only means of communication between the two sides of the heart was through a small opening (about $11 \mathrm{~mm}$. in circumference) in the upper part of the interauricular septum. This was, presumably, the foramen ovale, despite its high position. The left heart was insignificant in size, forming about one-eighth of the volume of the right heart. The only entry into the auricle was through the opening described. The mitral valve was small but otherwise normal. The aorta was hypoplastic (about $18 \mathrm{~mm}$. in circumference). The ductus arteriosus had closed and was represented by a fibrous cord. Many of these points can be seen in Fig. 4.

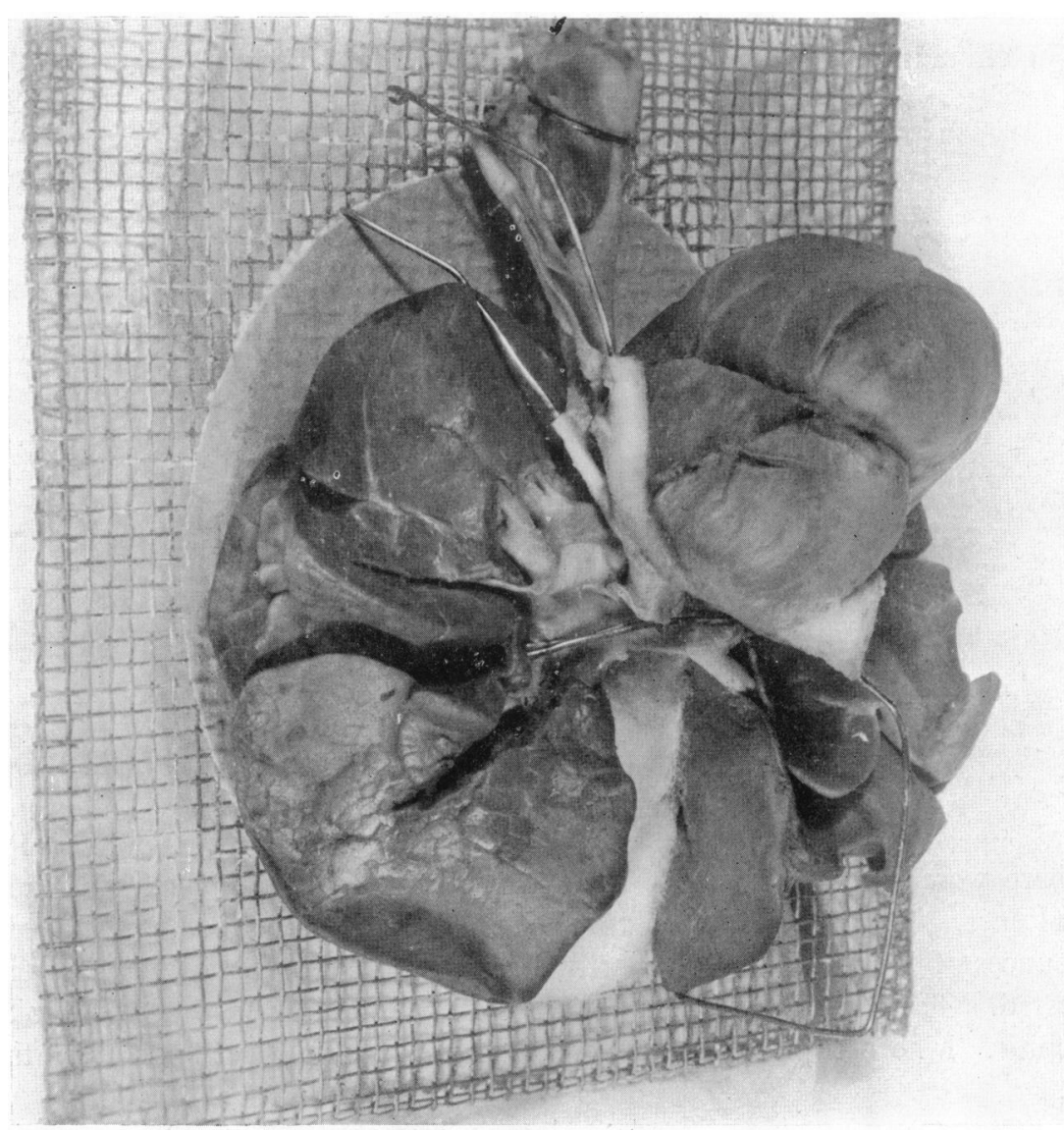

Fig. 3.-The anterior aspect of the preparation. The heart has been turned up and to the left so that only the hypertrophied right auricle and part of the right ventricle are seen. The single pulmonary vein is opened longitudinally, and its connection by a thick trunk with the superior vena cava is shown. 


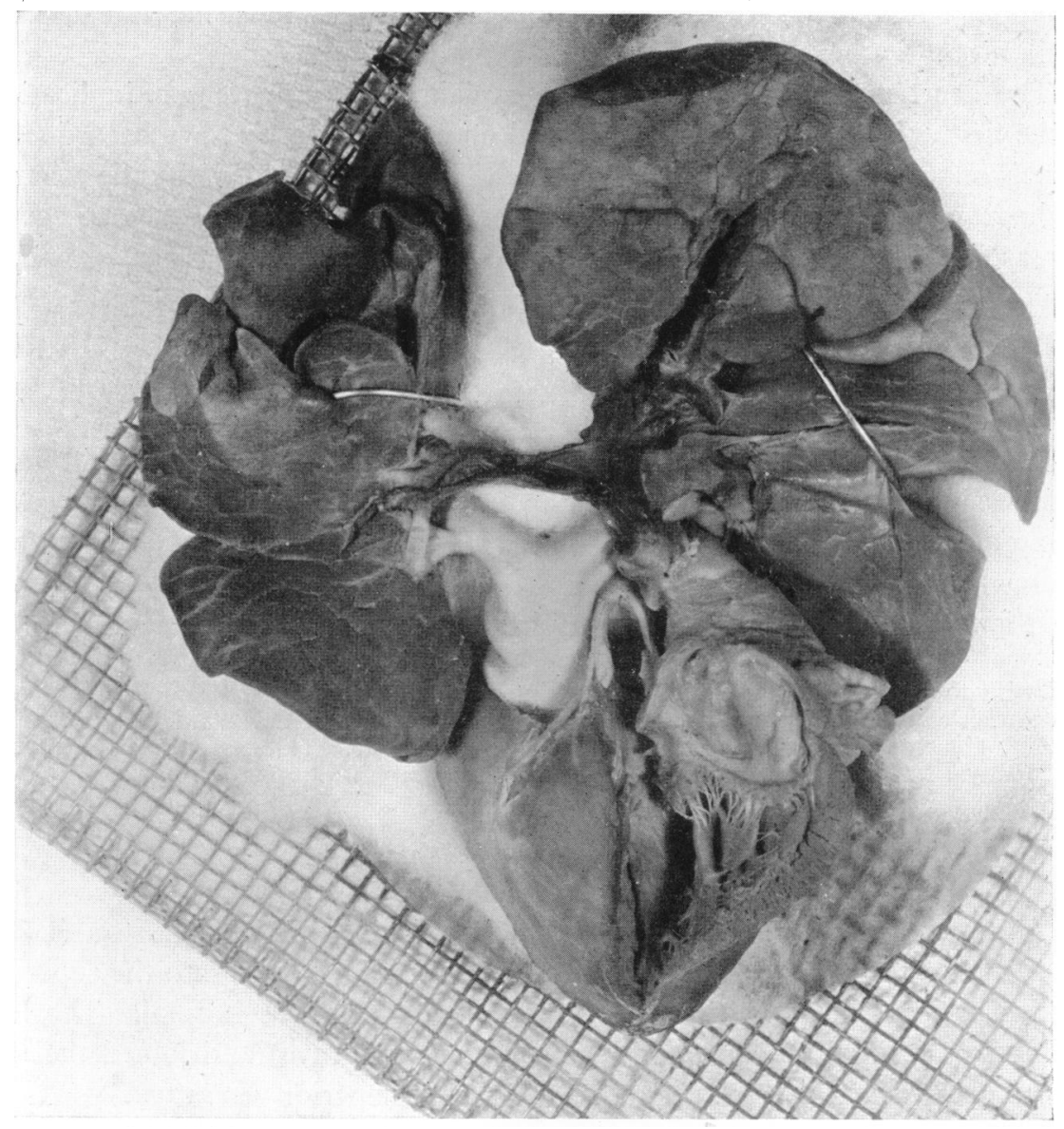

FIG. 4.-The posterior aspect of the heart. The lungs have been turned up. The left auricle and ventricle have been fully opened up to show their minute size. The small aorta and the dilated pulmonary vein are in apposition. Above is the single pulmonary vein and its communication with the superior vena cava.

\section{COMMENTS}

It appears that during the course of development the trunk formed from the pulmonary veins which enters the middle of the sinus venosus retained connection with the part of the sinus that ultimately becomes the superior vena cava. The part of the sinus venosus that forms the coronary sinus had separated normally. This arrangement would cause no embarrassment to the fœtal circulation, but with the closure of the placental circulation there was admixture of arterial and venous blood, with a consequent strain on the heart. Persistence of a patent ductus arteriosus would not have helped much, as this would have added to the work of the right ventricle.

Despite the persistent venous shunt, the heart maintained life for eleven weeks. Slight exertion was sufficient to produce embarrassment and cyanosis. It is strange that cyanosis was not manifest all the time, and that increased 
pulmonary resistance, due to bronchitis, instead of increasing it caused a diminution.

The heart murmurs are difficult to explain. The apparent reduplication of the first apical sound which was heard on admission may have been due to asynchronous ventricular contraction, but this is not supported by the electrocardiogram. The subsequent change in the murmur, with the development of increased pulmonary pressure, and the magnitude of the $P$ wave suggest that it may have been due to auricular systole.

\section{SUMMARY}

A case is described in which the only method by which blood could return from the lungs to the heart was through an opening into the superior vena cava. Communication with the left side of the heart was maintained by a patent foramen ovale.

It is believed that this abnormality has not been recorded previously.

I wish to thank Dr. Page, Medical Superintendent, for permission to publish this case. I also wish to thank Dr. Braithwaite, Consulting Physician, and Dr. Ward, Pathologist to the City General Hospital, Leicester, for their help, and Mr. Calder, senior Radiographer to the Royal Infirmary, Leicester, for taking the photographs.

\section{EDITORIAL NOTE}

A case, somewhat related, has been described by T. B. Johnston (1915) J. Anat. and Phys., 49, 182. The left pulmonary vein opened into the superior vena cava, but the pulmonary vein on the right side was normal. The left pulmonary vein passed upwards (left superior vena cava) and joined the left innominate vein, which passed across to join the superior vena cava. 